\title{
AUTOBIOGRAFÍA Y AUTORRETRATO
}

\section{LUIS PORTER}

Universidad Autónoma Metropolitana, Unidad Xochimilco

"Sólo quien no excluya nada de su existencia, ni lo que sea enigmático y misterioso, logrará sentir hondamente sus relaciones con otro ser como algo vivo, y sólo él estará en condiciones de apurar por sí mismo su propia vida."

"La verdadera patria del hombre es la infancia"

Rainer María Rilke (Cartas a un joven poeta)

RESUMEN

En este texto se afirma que la autobiografía es un género que introduce al que se decide a aplicarlo en el mundo de la creación literaria. Se hace una distinción entre el clásico texto académico, el ensayo, frente a la narrativa, que terminará recurriendo al arte y a la poesía, trascendiendo la emoción de sentirse inteligente para lograr una emoción menos experimentada por el académico, que es el placer estético. Para ilustrarlo, lo textose divide en dos partes, la primera es un texto literario autobiográfico contado como una conversación desde el afecto y la libertad; la segunda son una serie de elementos teóricos que se desprenden de dicho texto y que podrían explicarlo. Se sostiene que de todas las relaciones que establecemos con los demás, la más libre es la amistad que se da en una conversación libre. Esa es la conversación que sostenemos con nosotros mismos y con nuestros seres queridos, entre ellos, aquellos maestros inolvidables que forman parte de nuestra vida. La autobiografía termina siendo un recurso que nos permite recuperar la dignidad que los gobiernos envilecidos de nuestros países buscan quitarnos una y otra vez.

Palabras clave: Sueño. Poesía. Conversación. Amistad.

\section{ABSTRACT AUTOBIOGRAPHY AND SELF-PORTRAIT}

This article affirms that autobiography is a genre that introduces whoever decides to employ it to the world of literary creation. It is made a distinction between the classic academic text, or essay, and the autobiographical narrative that resorts to drawing upon art and poetry, transcending the emotion to feel able to achieve a sense less 
experienced by academics, which is the aesthetic pleasure. To illustrate this duality, this paper is divided into two parts. The first is an autobiographical text that, like a conversation, it is based on affection and freedom; the second brings theoretical elements, which are deduced from the first part and try to explain it. It is believed that, of all of the relationships we establish with others, the freest is the friendship that occurs in an unrestricted conversation. That is, or should be, the conversation we have with ourselves, and with our loved ones - among them those unforgettable teachers who form or have formed part of our lives. Autobiography is a recourse that allows us to give another meaning to ourselves, and by doing so, recovering the dignity that the undignified governments of our countries try to take away from us time and time again.

Keywords: Dream. Poetry. Conversation. Friendship.

\section{RESUMO}

\section{AUTOBIOGRAFIA E AUTORRETRATO}

Afirma-se, neste artigo, que a autobiografia é um gênero que introduz aquele que decide escrevê-lo no mundo da criação literária. Distingue-se o texto acadêmico clássico, que o é ensaio, em contraposição à narrativa, que recorre à arte e à poesia, transcendendo a emoção de sentir-se capaz de alcançar um sentimento menos experimentado pelos acadêmicos, que é o prazer estético. Como ilustração, o artigo divide-se em duas partes, a primeira diz respeito a um texto autobiográfico, narrado como uma conversação, a partir da afeição e da liberdade; a segunda traz elementos teóricos, que se depreendem da primeira parte e procuram explicá-la. Sustenta-se que, de todas as relações que estabelecemos com os outros, a mais livre é a amizade manifestada em uma conversação livre. Essa é a conversação que sustentamos conosco, e com as pessoas pelas quais temos apreço, entre estas, aqueles professores inesqueciveis, que fizeram e fazem parte de nossa vida. A autobiografia acaba sendo um recurso que nos permite recuperar a dignidade que os governos degradados de nossos países procuram repetidamente nos tirar.

Palavras-chave: Sonho. Poesia. Conversação. Amizade.

\section{Tropezar con sueños}

Al levantarse el telón, el público se enfrenta a un plano gris, diluido y borroso. El escenario es el recuerdo, y por lo tanto todo lo que en él aparece, no existe. Los detalles no son necesarios, solo aquellos que la memoria cree recor- dar. El momento en que se describe un largo itinerario o la circunstancia precisa de algún desencuentro, solo será una lejana referencia. El que escribe tiene una marcada inclinación por la geometría y por los símbolos, lo que le 
da al diálogo un sentido de vértice. La iluminación es irreal, la luz es interna como la que fluye de una pantalla, creando una atmósfera difusa. El vestuario es casual, lo que incluye la posibilidad de que ella calce sandalias y el, de todos modos, la sienta asombrosamente alta.

En ciertos momentos del diálogo un haz de luz se proyecta sobre otros actores que no juegan un papel activo. Todo sugiere una comunicación postergada, una historia de nostalgias y fronteras, de huidas, de búsquedas y de desencuentros. La música será un elemento extra-literario útil para cubrir algunas ausencias. La historia irá transcurriendo según el guión, como una acumulación algo inconexa de poemas escritos con anticipación o aún por escribirse. El relato surge como un collage, en el que recortamos y pegamos figuras de revistas infantiles, escritos escrupulosamente guardados en un atado sujeto con una cinta descolorida, borradores de poemas que dejamos para revisar mas tarde. Una especie de diario que no sigue un orden cronológico.

Hay un juego de telones transparentes que bajan y suben transformando la escena. A veces el escenario se oscurece, otras algún objeto del mobiliario adquiere un realismo inesperado. Todo ocurre entre actos, telones que bajan y suben, instantes en que los personajes, el público, los tramoyistas, la vendedora de boletos y hasta los acomodadores, aplauden. Instantes cuya imposible coordinación, y casi segura incoherencia, producen de todas maneras un final ideal, porque es una historia que no acaba, que nunca se detiene.

"Cada cual debe llevar el diario de algún otro" - dijo Oscar Wilde (1992) - 'insinuando que es dificil reconocer con claridad los otros que hay en uno. En vez de matar lo que uno ama, en fugaces e inútiles romances, deberíamos escribir nuestra biografía delineando el

1 Carta a Ada Leverson, Mayo, 1985, Selected Letters of Oscar Wilde, editadas por Rupert Hart-Davis. Oxford University Press, 1979 diario de algún otro. Por otra parte, un diario que me omitiera lo más posible me ayudaría a reconocer a ese otro que siempre busca asomarse. Cada instante es el fin de un ciclo, le damos importancia al final de una década como le atribuimos poderes al inicio de otra, no es mas que una manera de entusiasmarnos con los unos que se descubren en los otros. Nuestras extrañas formas de concebir el tiempo, facilitan la tarea de testimoniar algo, y a través de ello, quizás, reconocernos.

Nos encontramos con nosotros mismos, como resultado de regresar por el camino recorrido dando crédito a lo que fuimos, que es decir, a lo que seremos. Es el impulso por recobrar lo perdido, volver a nuestra juventud, por medio de lo que queda en el recuerdo y de lo que olvidamos sin tener conciencia de ello. Porque es para combatir el olvido que nos dirigimos hacia ese allá que está detrás del valle o de la sierra, a esos otros países que recorrimos para crear nuevas nostalgias, o el recóndito árbol genealógico que escudriñamos en pos de una identidad que se esfuma en el pasado. Nos refugiamos en el recuerdo mas lejano como en el que apenas se produjo. Siempre volvemos, y las cosas también vuelven a nosotros. $Y$ en estos continuos regresos tomamos distancia y vamos hacia el ayer con lo que pretendemos formar nuestro mañana. Nadie sabe porque los caminos se cruzan ni en donde comienzan las cosas. Nos encontramos con nosotros mismos en esa casa que minuciosamente construimos sin pensar en sus futuros habitantes. Nos encontramos en el jardín que sembramos y concebimos de la misma manera que escribimos esa historia que tiene la forma de la novela de algún otro. Regresamos al mismo jardín cuyos árboles sembramos y hoy dan sombra desde lo alto, y nos reconocemos en las figuras que el sol dibuja con sombras, al final, es el recuerdo el que nos contempla desde su tristeza. 
Escribir sobre lo que fuimos, es volver por los caminos donde pasamos una y otra vez. Es como regresar por el borde de aquel largo río, con su frío limpio y transparente, sendero que conocimos bien y hoy se vuelve a dibujar en los vestigios verdes que dejó el verano luminoso. Reconocemos esa orilla de arena color ocre. Todos necesitamos tropezarnos de vez en cuando con un sueño, aunque los sueños tengan el alto costo de la madrugada, sean intemporales e inenarrables, y terminen con la forma de un cuento o de un diario.

Caminar junto al río, navegar por el río, es como re-dibujar una línea olvidada. El río forma curvas en su lento viaje hacia el mar, genera puentes con escalinatas que parecen pentagramas. Puentes que nos recuerdan esos saltos sublimes de las bailarinas. ¿Cómo es posible vivir en sitios sin ríos y sin puentes? ¿Cómo vivir en una ciudad de la que no podemos enamorarnos? Aunque es imposible amar constantemente, se ama y después se regresa a lo que uno amó, como si uno se mirara desde una ventana. Se vive y después se regresa a los antiguos cuadernos en donde uno dejó borradores con relatos de lo vivido. Todos necesitamos tropezarnos con un sueño, aunque seamos nosotros mismos los que pongamos el despertador. Los sueños están hechos de las dudas de la oscuridad y el deslumbramiento de la luz temprana.

Matamos aquello que amamos, dijo Oscar Wilde, ${ }^{2}$ algunos lo hacen con la espada, otros con la palabra. Pero en mis conversaciones con Wilde le digo con cierta inocencia, que una vez que un amor nace, crece y nunca muere. Como lo dice Carlos Martínez en su poema Los Amores: "Una vez que un amor nace en uno, crece. $Y$ no deja de crecer". Al término de la vida, como

2 Wilde, Oscar. The Ballad of the Reading Gaol, (1897) en la primera parte del poema puede leerse: "And all men kill the thing they love,/By all let this be heard,/ Some do it with a bitter look,/Some with a flattering word,/The coward does it with a kiss,/The brave man with a sword!" en su transcurso, se encuentra uno como esos árboles rodeados de enredaderas, abrazado por esos amores que crecieron como bejucos. De nada sirve podarlos regularmente con las grandes tijeras del olvido, no podemos impedir su inexorable crecimiento. Se nos iría la vida en ese esfuerzo. Si el único destino de los amores fuera morir, habría que matarlos antes de su nacimiento, porque una vez sembrados, son como una semilla que germina, como un puñado de tierra fértil nutriendo ese tallo sin detenerse. Es necesario tropezarnos con un sueño, porque cuando el sueño se atreve a la claridad, cuando se abre a la luz temprana sin perder su calidad de sueño, entonces crece y florece, se convierte en poema y nos acompaña por el resto de nuestra vida. Los sueños hechos realidad son los que pueblan y dan vida y color a nuestro jardín.

Dicho esto, el escenario se llenó de luz, hasta que no fue posible distinguirla de la oscuridad.

\section{Aprender a soñar}

Ser capaces de asomarnos al lenguaje desde la poesía, es decidirse a incorporar nuevos matices a nuestro texto. Como académicos, hemos sido educados para escribir ensayos, y cuando bien nos va, un buen texto nos lleva a sentirnos inteligentes. Escribir como quien aborda una conversación desde el afecto, nos lleva a experimentar algo diferente, el placer estético. Ser inteligentes es diferente a ser sensibles. La sensibilidad es el camino del arte. Abandonar el texto formal del ensayo, para transformarlo en un relato, nos abre nuevas perspectivas $y$ hace uso de otros poderes. Poner a trabajar al cerebro desde la sensibilidad equivale a convocar las virtudes de Pandora: la belleza, el talento musical y el don de sanar.

La autobiografía no trata de teorías, sino de casos específicos, de abordajes narrativos que terminan siendo participativos, porque se 
inicia como una experiencia meramente personal, un monólogo, con su tono racional, lógico, que deriva en diálogo, y entonces se bifurca en proliferaciones, cruzamientos y aperturas, como si alguien nos dictara y la mano obedeciera. Es así como en ese diálogo con los otros que llevamos en nosotros, la mano dócil y obediente dibuja una narrativa que va tomando la forma de una expresión artística, llena de alusiones atinadas, que no sabemos a ciencia cierta como aparecieron en nuestra imaginación. El elemento creación entonces, no reside en la inteligencia, en el cultivo del conocimiento, sino, en principio, va al rescate de esos veneros internos que alimentan la imaginación, la intuición, invitados que se manifiestan sin trabas, y permiten experimentar que esa capacidad creativa no es diferente a la que camina junto a las grandes obras. Se trata de una transformación que requiere, antes, primero, un profundo respeto y conocimiento del lenguaje, difícil de lograr, y segundo, la libertad que debió preservarse desde la niñez, de las épocas de estudiante, sin haber perdido su espontaneidad, su entusiasmo tembloroso que tiene algo de luz, de compás musical, germen de la felicidad que se expresa en maravillosa alegría. En suma, convocar las imágenes visuales literarias nos abre un camino diferente al de las hipótesis, variables y proposiciones propias del empirismo.

Patrick Diamond y Carol Mullen (1999) definen esta afirmación diciendo que una historia contada con arte es una respuesta en la que se le da forma y sentido a la experiencia. Cuando nos liberamos de la pura racionalidad, "ordenamos y reconsideramos nuestra experiencia buscando aprender y compartir algo acerca de nosotros mismos y al hacerlo, despertamos al artista que llevamos y al que existe en los demás". La literatura actual cuando tiene calidad, desafia y amplía la forma en que respondemos a la vida, profundizando nuestro pensamiento acerca de la condición humana. La diferencia de un texto convencional, y uno que intenta contar una historia para deleite artístico, abre nuevas posibilidades de identidad, de pensamiento $y$ acción y tiene un diferente efecto en los demás, en la medida en que nos vemos como artistas capaces de crear nuestras propias "historias" de experiencia y desarrollo personal.

Para reconocer nuestro espíritu artístico debemos comenzar tomando en serio aquellos cuentos, poemas, ensayos, auto-narrativas y visualizaciones, que constantemente pasan por nuestra mente o por nuestras manos y que dejamos ir sin darles importancia. Se trata de un cambio que implica, si somos estrictos, una lectura abierta y un nuevo mapa del arte y la educación, del yo y el otro, de la reflexión y la acción. Esto no se logra por medio de discursos abstractos, sino de la visualización de "mundos" y un mundo, según Diamond y Mullen (1999) es por definición "una actitud hacia la complejidad de la experiencia". Para eso se necesitan nuevas formas de representación que transmita lo que los educadores artísticos experimentan y aprenden. Estos hallazgos surgen de aspectos de la experiencia que se transforman en imágenes visuales, procesos literarios, metáforas, figuraciones, entre los que la narrativa es un ejemplo, nada más. ¿De que se trata entonces el cambio propuesto de contarnos nuestras vidas desde la poesía?

- De profundizar en el entendimiento de la experiencia de uno mismo y de los otros, o de uno en relación con los demás.

- De utilizar estrategias basadas en el arte (forma con contenido) que se reflejan en la experiencia e invitan a otros a responder a este tipo de indagación.

- De repensar y promover nuestro desarrollo como (investigadores-estudiantes-egresados) por medio de actividades artísticas que puedan promover una forma de entender y ver el entorno. 
- De incluir el uso de múltiples formas creativas que den una expresión ordenada a sentimientos personales, ideas imaginativas, temas de interés.

- De entender la experiencia de nosotros mismos, en relación a los que participan con nosotros y del mundo cambiante, para definir nuestra actuación y nuestro desarrollo como un tipo de "conocimiento profesional que tiene un sentido de expansión y la posibilidad de llenarse con lo diverso de las cosas de la gente, eventos y relaciones" (Dewey, 1938, 1950, 1958); (CLANDININ y CONNELLY, 1996, p. 139).

Hemos crecido pensando que existen genios creadores por un lado, y que existimos nosotros, por el otro. Nos han enseñado que existen seres talentosos e iluminados, y que existimos nosotros, que no tuvimos esa suerte. En lugar de meternos dentro de nuestro marco teórico personal, y estudiar temas y problemáticas asociadas con nuestra autobiografía mental, existe la tendencia a consagrar a algún autor y nunca vernos a nosotros como autores que conversan con otros autores. Olvidamos que la relación entre el lector y el escritor es una relación activa, en la que los lectores recrean significados para ellos mismos. Esta relación entre el creador y el que recrea lo creado, tiene el potencial de adquirir una nueva dimensión en el conocimiento que surge del cuenta-cuentos (el story-teller) cuya audiencia tendrá la oportunidad de re-de-construir sus textos. Eisner (1991) nos dice "los humanos no tienen simplemente experiencias, sino que colaboran en su creación, y la calidad de su creación depende de la manera en que emplean sus mentes". Los artistas no son pequeños dioses, decía Pablo Neruda (1971) - en su discurso de aceptación del Premio Nobel - los poetas no son iluminados, al contrario, son como el panadero que cada mañana ofrece el sencillo producto de su trabajo.
Neruda nos sugiere que debemos repensar la metáfora del iluminado y de superarla, porque toda metáfora basada en la luz como fuente de acumulación de conocimiento implica un receptor pasivo de rayos de una fuente de sabiduría que emana de algún planeta distante. La idea de un ente estable, integrado y consciente que da luz, podríamos sustituirla por la de una comunidad de múltiples seres que brillan, es decir, que reflejan algo, en forma fluida, con constante movimiento y cambio, luchando por mantener dicha conciencia viva. Una comunidad en la que hay diferentes voces y diferentes posiciones, que abiertamente se contradicen, sosteniendo una cosa, luego otra y aún otra más, y que en conjunto definen "una situación", este concepto es la base de la "Planeación estratégica situacional" (PES) método creado por el chileno Carlos Matus (1983). que combate el individualismo exacerbado $y$ promueve el acercamiento a los otros. En este conjunto cualquier actor, como cualquier texto, no es "una línea de palabras que propone un solo sentido, como si se tratara del mensaje de un autor-dios, sino un espacio multidimensional en la que una variedad de escritos, ninguno de ellos único u original, se mezclan o chocan" Barthes (1977, p. 146) ${ }^{3}$.

Nuestra labor humana, como autores de nuestra biografia, debería manifestar esta conciencia, con un tipo trabajo que no busque agotar los recuerdos, situarlos en orden cronológico, o llegar a ser ejemplar, listo para circular en el mercado del conocimiento, sino presentar respuestas para las que no hay una metodología precisa, porque no están guiadas por reglas preestablecidas. Sin embargo ello no implica renunciar al rigor y al milagro del encuentro con el conocer en el camino de la ciencia, que al abordarse asumiendo nuestra capacidad artística, reflexionando sobre no-

3 PDF en http://dss-edit.com/prof-anon/sound/library/Barthes Roland_-Image Music Text.pdf 
sotros mismos, con la arbitrariedad propia del cerebro que sabe mas de lo que podemos explicar, toman la forma de una serie de eventos únicos que emergen de la acumulación de experiencias cotidianas.

Cuando hablamos de utilizar el arte, de hacer uso de nuestra capacidad artística como una visión instrumental en donde el arte es una herramienta de conocimiento, de búsqueda y no arte por si mismo, como un fin en si mismo, estamos pisando ciertamente un terreno nuevo. Llegar a una nueva conceptualización de nosotros mismos, obliga a una preparación que requiere experimentar, entrenarnos. No se trata de lograr una "capacidad estética" dentro de una visión del arte como algo reservado a unos cuantos que poseen un particular talento. Debemos superar el juego del artista-supra talentoso, del genio, y dejar de pensar en la actividad artística como un área exclusiva de aquellos excepcionales con raros dones, de los que hay uno en muchos millones. Tenemos, en cambio, que verla como un área potencialmente inclusiva en su capacidad de comprometer y transformar a los individuos, es decir, a nosotros mismos. Decir que "todos somos artistas" no es una frase retórica. Los que se encuentran comprometidos con el conocimiento: en adquirirlo, darlo o desarrollarlo, son implícitamente hacedores artísticos por nacimiento, como debe de serlo necesariamente un buen científico, un ingeniero o un físico. Todos estamos capacitados para sacar experiencias de nuestra condición ordinaria y convertirla en algo especial.

Al proponer o sugerir que el desarrollo como investigadores, futuros profesionales, expertos en determinada área del conocimiento, son formas de "arte", le estamos devolviendo al concepto de "arte" su antiguo uso, de "arte como diseño de artefactos útiles" (CLIFFORD, 1984), el arte similar a la poesía del que elabora el pan de todos los días. Un tipo de tarea en donde nuestras vidas y nuestros textos se interceptan con otros y nos enriquecen o nos enriquecemos mutuamente, ganando todos (YÁÑEZ, 1993). De la misma manera que le debemos al romanticismo la libertad del artista (BERLIN, 1999) y el hecho de que ni el artista ni ningún otro ser humano o grupo puede explicarse con visiones simplificadas como las que prevalecen en muchas mentes contemporáneas y cuyos análisis ultra-cientificistas o ultra-simplificados lejos están del justo medio que nos ubica entre valores incompatibles entre sí. Las ciencias sociales que apostaban a un sólo ganador, porque pretendían llegar a conclusiones en nombre de cierta forma de conocer, de cierta metodología, donde solo una de dos teorías opuestas, podía considerarse "correcta", va dejando sitio a un mundo nuevo, contrastante del anterior, donde aceptamos el conflicto, la turbulencia, la ambigüedad y la inestabilidad, para encontrar el rumbo que nos lleve nuevamente a tierra firme, para seguir navegando en un espacio más igualitario donde cada uno llegue a ser un ganador artístico.

Cada uno de nosotros, educadores, estudiantes, egresados, estamos requeridos a redibujar nuestros propios retratos, y al hacerlo, también el de nuestra familia, nuestros maestros y las instituciones en las que estudiamos o trabajamos. Estamos obligados, si no queremos simplemente flotar a la deriva empujados por la inercia de las cosas que nos llevan hacia donde no queremos, a ser creadores, héroes, escritores, artistas, intérpretes y teóricos. No es posible abordar la autobiografia sin, al hacerlo, abrir los ojos del artista imprescindible que permite poder ver. Recurramos a ella, hagamos uso de ella, después de todo, la llevamos con nosotros, y tan sólo se trata de recobrar esa forma de mirar, para lograr una verdadera "re-visión". Todo ser humano es un poeta que puede provocar emociones y emo- 
tividad en su lector o en quien lo escucha o lo ve, a partir del contrato de confianza que tácitamente firmamos cuando nos disponemos a expresar y formular lo vivido cotidiano desde donde la memoria lo decida, envolviendo las estructuras sociales, formales e informales. En ello estriba su aporte fundamental a la investigación social.

\section{Del sueño y la palabra}

Los caminos del texto autobiográfico, se deslizan entre el ensayo que se puede concebir como un producto intelectual apoyado en determinada idea de la historia, un estudio representativo de lo que uno fue, que busca tocar tierra firme, o como la palabra que toma vuelo para elevarse por trayectorias imaginarias, que en su intento de reflejar lo no-ficcional, terminan sin poder escapar de la ficción, con la imaginación de lo que pudo ser, en un lenguaje que no le teme a la poesía, ni a explorar el mundo artístico, o entreverarse con problemas estéticos. Borges es un ejemplo del autor que se aleja del ensayo puramente inteligente, Alfonso Reyes, en México, es mas fiel a lo figurativo. Personajes del exilio español trajeron nuevas maneras de vincular el pensamiento filosófico con el pensamiento ensayístico: José Gaos, María Zambrano, Tomás Segovia.

Confluyen en la autobiografía las dimensiones del ensayo y del espacio libre, en el que el escritor abandona momentáneamente su dialogo interno, para conversar con el lector, como parte de la interacción propia de relaciones humanas significativas, como la del hermano con la hermana, la del esposo con su esposa, la del alumno con su maestro, porque de todas las relaciones que establecemos con los demás, la más libre de todas es la amistad que se da en una conversación libre. El que escribe su historia, no busca apoderarse de la voz del otro, sino contar su vida, no como un monólogo sino como un intercambio de amistad, un espacio de libertad, similar al que se establece alrededor de la mesa de un café, para atrevernos a pensar el mundo, a conversar en torno a las palabras, estableciendo una charla entre amigos, que no difiere de una charla entre escritores. El tiempo de la autobiografia, es el tiempo de conversar, de compartir el proceso de escritura, tanto como los capítulos y el producto final, la amistad que nace en torno a la escritura como práctica de sociabilidad.

En este agregado final, abundaremos sobre los factores que puedan dar profundidad a dichas miradas que se intercambian, para alejarnos de lo trivial e intrascendente. "El vicio supremo es la superficialidad", (HART-DAVIS, 1979) fue quizás lo más importante que Oscar Wilde dijo en su De Profundis, esa carta autobiográfica que ha dejado testimonio de su profunda humanidad. Nos mueve la búsqueda de la verdad y nuestro amor por la belleza lo que equivale a decir, la búsqueda de la verdad por el camino de la belleza, que no es otra cosa que ua definición del arte. ¿Qué implica esta definición?, que el camino justo para que esta mirada abarcadora sea capaz de profundizar, es el camino del arte. Todos y cada uno de nosotros estamos en condiciones de desarrollar una mirada artística. Todos somos artistas, aunque no todos lo queramos vivir así, aunque no todos tengamos conciencia de ello o lo asumamos de esa manera. El arte es un producto humano, no un producto de la naturaleza. Una puesta de sol no es arte, como tampoco lo es una flor o la danza del colibrí frente a dicha flor. Aunque la naturaleza nos regale constantemente con imágenes bellas, la belleza no es suficiente para hacer del arte arte mientras no intervenga la mano del ser humano. ¿Qué es lo que nos hace artistas? André Compte-Sponville en su pequeño libro titulado "Invitación a la filosofia" define el arte como el sitio donde "la humanidad se contempla a sí misma, en la medida en que se cuestiona y cuestiona al mundo, 
en la medida en que busca verdad y significado, en la medida en que cuestiona e interpreta, en la medida en que razona." (2002, p. 117) ${ }^{4}$

El ser humano es el que transforma y recrea a la naturaleza, aunque no siempre lo haga con arte, ya que lamentablemente es posible vivir una vida no artística, una vida sin arte. Pero cuando uno descubre que el arte puede y debe ser parte de nuestro devenir cotidiano, cada una de nuestras jornadas adquiere mayor riqueza y trascendencia. Es diferente vivir distraído por los valores que hoy dominan, como son el egoísmo, la racionalidad, la desconfianza; es diferente vivir tratando de ser funcionales, eficientes, de tener más poder en nuestra mínima parcela, que vivir conscientes de nuestras capacidades y alertas en el búsqueda de nuestro ser auténtico. Lo que distingue a una persona que ha tomado conciencia de su capacidad artística es la búsqueda por conocer y entender al mundo, que es decir, a si mismo. Pero esta búsqueda no puede ser obtusa en su rango y superficial en su foco. No basta con mirar, imitar, copiar, o simplemente aparentar. Embellecer no es colgar un cuadro en la pared o pintar la casa de determinados colores. El arte no es una mera representación de la belleza. Imitar es tan solo un medio. El artista no copia, el artista crea. (No basta con seguir convenciones, con respetar tradiciones, con ser obediente, todo ello nos puede ayudar a reproducir vidas vividas pero no a crear la nuestra propia). La belleza que produce una vida artística no se detiene en la belleza del mundo cotidiano, ni en la que nos ofrece la naturaleza (flores, puestas de sol, pájaros, estrellas) es algo más, es algo que tiene que ver con la verdad que surge del ser humano, quien a través de su conciencia existe para el mundo pero también existe para sí mismo.

El hombre recurre al relato de su vida, utili-

4 Puede leerse en http://www.sophipolis.net/pdf-materiales/Comte_Invitacion-filosofia.pdf zando a la poesía como medio, para "externalizar lo que es", para encontrar en esa expresión, su propia interpretación, un "reflejo de sí mismo". El ser humano, académico o no, obrero o campesino, ama de casa, empleada o estudiante, contempla al mundo y trata de darle sentido. Al hacerlo, también se contempla a si mismo, y al hacerlo se cuestiona, y al cuestionarse, se reconoce a si mismo en ese acto de contemplar, de ver para conocer. Es justamente esta capacidad de reflexionar, que al encarnarse, al hacerse tangible, se transforma en obra de arte. De acuerdo al filósofo francés Emile Chartier: "Todas las artes son como espejos en los que el hombre aprende y reconoce algo de si mismo de lo que antes no tenía conciencia" (1955, p. 67). Esto no quiere decir que la autobiografia por medio del arte sea para mirarse sólo a si mismo. Su mirada puede abarcar todo lo que se encuentre a su alcance, sin dejar de tener conciencia de si mismo en el acto de mirar. El verdadero espejo en el que el hombre se busca a si mismo es el mundo. El arte no es más que el reflejo en el que el hombre se encuentra a si mismo.

¿Qué se necesita entonces para ejercer nuestra capacidad artística cuando intentamos relatar nuestra vida? No se necesitan talentos especiales. Solo abandonar toda excusa y no poner condiciones al estar dispuesto a confrontarse consigo mismo. El que inicia sus memorias, inicia un acto de creatividad, y para crear, según Kant (2007), "no existen reglas determinadas" 5 . Como docente dedicado a introducir a estudiantes muy jóvenes al mundo de la arquitectura, me he preocupado por dejar claro que no existen fórmulas o instrucciones efectivas para desarrollar la creatividad en el estudiante. Los jóvenes nos sorprenden constantemente con lo que sus manos aun inex-

5 KANT, Manuel. Fundamentación de la Metafísica de las Costumbres, 2007. (dominio público) http://www.filosoficas.unam.mx/ gmom/clasicos/kant-fundamentacion.htm 
pertas hacen para materializar buenas ideas. Al hacerlo actúan como si alguien les estuviera dictando desde adentro lo que deben hacer. Muchos colegas han hecho y siguen haciendo interminables esfuerzos por transcribir esa voz interior en forma de reglas. En su obsesión por encerrar la creatividad en fórmulas, hablan de "métodos" de "procesos de diseño", creando un espiral de esfuerzos en vano. Caminos previamente estipulados que no siguen la huella de los que hacen camino al andar, no hacen artistas. No parece posible (ni necesario) reducir el proceso creativo a "dar los siguientes pasos". Los entrenamientos severos no lo son para el que se somete a ellos, cuando se hace desde la libertad. Son otros los ejercicios inevitables que hacen evidentes los otros caminos, los misteriosos implícitos en el ser humano, que lleva muchos nombres, duende, alux, genio, cofre negro, magia, revelación, Dios.

Los que se detienen a reflexionar, como los que reflexionan sin detenerse, los que meditan frente a un muro blanco, como los que se quedan extasiados mirando el cielo, son al tiempo originales y ejemplares. Dos condiciones, relacionadas con la manifestación de lo que somos, por medio de la excepción, única regla en arte.

¿Qué es lo que hace la biografía como ensayo poético algo precioso? Que nos revela a nosotros mismos en la búsqueda de nuestra verdad, como sujetos poseedores de belleza, aun cuando su forma o su contenido tengan rasgos feos y banales. Ser una persona común y corriente, no importa, porque al buscar explicarse, es ese acto y no su imagen, la que lo hace bello. Una lata de sopa Campbells, para Warhol, o un par de manzanas, una pera y un platón, para Cezanne, un par de notas musicales, para un compositor, son elementos simples, que no significan nada en sí mismos, pero que adquieren en las manos del artista, la capacidad de revelarnos algo. Los libros no son me- jores que la vida, ni los escritores viven más intensamente, pero lo que escriben nos permiten entenderla y apreciarla más, percibir y habitar mejor nuestra vida. Poca gente percibe que su vida es tan intensa, dramática, profunda y plena como la de los personajes que admira en una novela, o en una película. El arte en su singularidad nos revela eso. Para aprender del arte a apreciar el arte de nuestras vidas, necesitamos belleza y necesitamos verdad, no por separado, sino como una unidad. Por eso necesitamos sentarnos a escribir, tomando ejemplo del arte, no para embellecer colgando algo en un muro, alineando libros en un estante, sino para revelar y hacer manifiesto la belleza intrínseca que existe en la vida, y aprender a verla y disfrutarla. El arte manifiesta la verdad de la existencia (escribió Heidegger), por lo que existir en la verdad es ser artista. No la verdad de la ciencia, no la verdad del expediente que guarda las evidencias, ni la verdad teórica, con sus conceptos, teorías y abstracciones, sino la verdad del arte, que es siempre concreta, práctica, silenciosa (aun cuando se exprese en palabras, en imágenes, en sonidos). La verdad de ser, tan lejos como lo logremos, es "estar en la búsqueda de nosotros mismos, en la búsqueda de ser". Escribir desde la poesía es tratar de vivir lo humano, es asumir nuestra condición humana con sus ritmos, su manejo del lenguaje, sus metáforas, su desbordada imaginación. Sin embargo, la finalidad última no es la belleza, ni la destreza técnica, sino la revelación. En arte, la única belleza que importa es aquella que no miente. El arte es producto del ser humano, y e ser humano producto del arte. El arte se inspira en la naturaleza, pero como dijo Oscar Wilde, (2013, p. 43) es la naturaleza la que termina imitando al arte.

\section{Final}

Decíamos que de todas las relaciones que establecemos con los demás, la más libre de todas 
es la amistad que se da en una conversación libre. Quiero finalizar este artículo conversando y evocando a un maestro que tuve durante un curso de ingreso a la Facultad de Arquitectura en la UBA de Buenos Aires, el Dr. Gregorio Weinberg. Este gran maestro, se dedicó a abrir horizontes mentales a través de una de las mejores estrategias pedagógicas: hacer que el alumno se deslumbre ante la infinita variedad y complejidad del mundo y se interese por indagar sus enigmas. Las huellas que el dejó, (quizás debiera decir las semillas), germinaron de diferentes maneras, una de ellas fue la de concebir la autobiografía como una modalidad del trabajo educativo. Otra fue complementar la oralidad propia de la academia, "la clase" por el texto escrito, redactar lecciones, llevarlas escritas a los alumnos, acumularlas hasta resultar en un proyecto editorial. Con el profesor Weinberg, los estudiantes vivíamos la "toma de conciencia" de nuestra especificidad, de la legitimidad y viabilidad de nuestros incipientes proyectos. En grupos multitudinarios, adonde también asistía Rolando García, nuestra inserción en el mundo contemporáneo, ocurría por medio de la introversión que esta en estrecha relación con nuestro pasado, para regresar al presente, reafirmados en nuestra identidad, y así proseguir con la búsqueda de una dimensión futura propia. ¿Cuál fue nuestro tiempo? ¿Qué papel jugamos en nuestra juventud? ¿Cómo concebimos el tiempo, nuestra trayectoria en el tiempo? ¿Cómo llegue a ser lo que hoy soy? Transcurriendo por los cambios de sociedad y de cultura, emigrando del país natal al México insondable, que me obligó a renacer como indígena transformando mi visión de mundo después de décadas de experiencia social en el país tan diferente y lejano.

Nuestros maestros nos han ido llevando por ejercicios del pensamiento, que nos devuelven vivos del periplo al que la envilecida política nos obligó dar. Fuimos dejando de creer en las personas y creímos mejor en las palabras, hasta que nos dimos cuenta que nuestra herencia no es un legajo de papeles, ni un expediente, sino ecos y espejos. La apertura, la libertad, la capacidad crítica de entender los procesos, la capacidad de explicar, antes de concluir, teniendo como guía la curiosidad, y la convicción de que cada espacio de conversación, es un salón de clases, nos ayudaron a sentir que comprendíamos. Enseñanzas escolares, enseñanzas hogareñas, van o y vienen de la mano. En el contexto turbulento, avanzamos del desahucio a la promesa, del desconsuelo a la esperanza. Hablamos de un maestro, pero fueron muchos los que jugaron u papel fundamental para el crecimiento, la puesta en diálogo y la consolidación de nuestras ideas. Repetimos el ejemplo y dedicamos con entrega, una gran parte de nuestro tiempo a las tareas docentes. Hoy hemos cerrado un amplio ciclo como investigadores y como profesores, por eso decidimos dedicarnos a escribir nuestra autobiografia, lo hacemos conversando con nuestros amigos, recordando y venerando a nuestros maestros, viajando a lugares que no conocíamos, regresando a los lugares que nos vieron jugar de niños. Pienso con la hija de Weinberg, Liliana, que tampoco su padre se equivocó en su magna apuesta por la educación, y por pensar que la viabilidad de su país, como de tantos otros hoy en plena crisis, "como proyecto capaz de ir del pesimismo de los cuellos de botella al optimismo de un futuro compartido pasaba necesariamente por un rescate no tradicionalista de la tradición que debía empezar por reconocer la legitimidad y la mayoría de edad de nuestra existencia como entidad de cultura y por ende nuestro derecho a hacer memoria, construir y acumular memoria"6. Hagamos memoria, sigamos construyendo bibliotecas,

6 Palabras leídas por Liliana Weinsberg, en la apertura de las XV Jornadas Argentinas de Historia de la Educación "Tiempo, destiempo y contratiempo en la Historia de la Educación", Salta. 2009 
como hizo Weinberg, recuperemos la dignidad, recuperando a nuestros clásicos, aprendamos a releer, hagamos el ejercicio de relatar nues- tro itinerario, nuestra vida, como forma de recuperar la memoria, como testimonio hecho de tiempo, destiempo y contratiempo.

\section{REFERENCIAS}

BARTHES, R. Image music text. New York: Hill; Wang, 1977.

BERLIN, Isaiah. The roots of romanticism. The AW Mellon Lectures in the Fine Arts, Bollingen Series XXXV 45. Princenton: University Press, 1999.

ALAIN, Emile A. Chartier. Veinte lecciones sobre Bellas Artes. Buenos Aires: EMECE, 1955.

CLANDININ, D. Jean; CONNELLY, F. Michael. Narrative inquiry, experience and story in qualitative research. San Francisco: Jossey-Bass Publishers, 2000.

CLIFFORD, J.; MARCUS G. (Eds). Writing culture: the poetics and politics of ethnography. Berkeley, Ca: University of California Press, 1984.

COMTE-SPONVILLE, André. Invitación a la filosofia. Barcelona: Paidos, 2002.

DEWEY, J. Education as experience. New York: Macmillan, 1938.

Democracy and education. New York: Macmillan, 1950.

Art as experience. New York: Capricorn Books, 1958

DIAMOND, C. T. P.; MULLEN, C. A. (Eds.). The postmodern educator: arts-based inquiries and teacher development. Canada:Peter Lang, 1999.

DIAMOND P. C. T.; MULLEN C. A. (Coeditors). The postmodern educator: arts-based inquiries and teacher development. Canada: Peter Lang: 1999. (Counterpoint series, 89).

EISNER, E. W. The enlightened eye: qualitative inquiry and the enhancement of educational practice. Old Tappan, N. J.: Macmillan, 1991.

HART-DAVIS, Rupert. Selected letters of Oscar Wilde.
Oxford: Oxford University Press, 1979. (Contiene la carta titulada "De Profundis, in carece et vinculis")

KANT, Manuel. Fundamentación de la metafísica de las costumbres. Traducción de Manuel García Morente. San Juan, Puerto Rico: Edición de Pedro M. Rosario Barbosa, 2007. (dominio público). Disponible en: <http://www.filosoficas.unam.mx/ gmom/ clasicos/kant-fundamentacion.htm>. Acesso en: 20 marzo 2016

MATUS, Carlos. Elementos de panificación estratégica, política y plan en situaciones de conflicto. Venezuela: CENDES, Universidad Central de Venezuela, 1983.

NERUDA, Pablo, Discurso pronunciado con ocasión de la entrega del Premio Nobel de Literatura, 1971. Disponible en: <http://www.mundolatino.org/cultura/neruda/neruda 3.htm>. Acesso en: 10 enero 2015

WEINBERG, Liliana. El tiempo de Gregorio Weinberg, Reseña de eventos. Hist. educ., Ciudad Autónoma de Buenos Aires, anu. , v. 10, p. 15-30, dic. 2009.

WILDE, Oscar. La balada de la cárcel de Reading. Traducción y prólogo de Jesús Munárriz. Ilustraciones de John Vassos. Edición bilingue. Madrid: Ed. Hiperión, 1992.

WILDE, Oscar. La decadencia de la mentira. Madrid: Ediciones Siruela, 2013.

YÁÑEZ, Ricardo. Notas para despedirse de un taller. Revista La Tarea, Guadalajara, Jalisco, p. 41-41dic. 1993. Disponible en: <http://www.latarea.com.mx/ indices/indice1.htm>. Acesso em: 15 enero 2015

Recebido em: 30.03 .2016

Aprovado em: 10.09.2016 
Luis Porter Profesor fundador de la Universidad Autónoma Metropolitana, Unidad Xochimilco. Es Dr. en Educación por la Universidad de Harvard (HGSE); Maestro en Planeación por el Instituto Tecnológico de Massachusetts (MIT / SPURSDUSP); Maestro en Urbanismo y Arquitecto (UNAM). Su trabajo como investigador gira alrededor de dos líneas básicas: 1) Los Estudios sobre el sistema de universidades públicas mexicanas; 2 ) Los Estudios sobre la Juventud, en el marco de la salud mental, enfocado en los estudiantes del primer año universitario, que se concreta en el proyecto: "Cero-veinte: el primer año de universidad como reflejo de los primeros años de vida" que constituye la "Red internacional interdisciplinaria Cero-Veinte" (RII-0/20). De sus recientes publicaciones destacan: La Universidad de Papel $(2003,2007,2013)$ UNAM; Entrada al Diseño, estudiantes y universidad, UAM-X (2009) y "El Libro de la Universidad Imaginada" (2012) Juan Pablos/UAM-C. Es investigador del Sistema Nacional de Investigadores (SNI) Nivel 2. E-mail: vlporter@yahoo.com

Prol. Canal de Miramontes 3855, Tlalpan, Ex Hacienda San Juan de Dios, 14387 - Ciudad de México, D.F., México 